\title{
К ВОПРОСУ О ПОНЯТИИ ДЕФЕКТА ЮРИДИЧЕСКОГО ДОКУМЕНТА
}

Аннотация: В современном мире роль документооборота существенно возросла, в том числе в нашей стране. С переходом к рыночной экономике юридические лица, индивидуальные предприниматели, иные субъекты стали полноправными участниками гражданско-правовых отношений, сопровождающихся различными правовыми документами. Также идет активный процесс развития новых сфер общественных отношений, нуждающихся в правовом регулировании. Однако, несмотря на позитивную тенденцию развития права, многие юридические документы содержат те или иные дефекты, что препятствует должной реализации прав и свобод человека, создает затруднения для развития общества и государства. С целью формулирования качественного определения категории «дефект юридического документа» были проанализированы признаки данного явления. В ходе исследования использовались философский, логический, грамматический и сравнительно-правовой методы. Несмотря на актуальность рассматриваемой темы, на сегодняшний день не существует комплексного исследования, касающегося выявления сущности десректа юридического документа. Однако невозможно решить частную проблему, не обращаясь к ее фундаментальному основанию. В статье анализируются признаки дефекта юридического документа и формулируется определение данной категории. Это способствует очерчиванию грании проблемы, дальнейшей разработке теоретических и практических механизмов выявления, устранения, предотвращения дефектов юридического документа, а также причин и условий, способствующих их возникновению.

Ключевые слова: десрект юридического документа, качество, юридическая техника, правовое регулирование, изъян, деятельность, юридическая ошибка, содержание, форма, потребности DOI: 10.7256/1994-1471.2014.6.11547

$\prod_{\text {дения. }}$ ефект юридического документа - одна из важнейших категорий юридической техники и юридического документовеконятие качества юридического документа обеспечивает правильное представление о состоянии отраженных в юридическом документе правоотношений ${ }^{1}$. Понятие дефекта юридического документа охватывает различные отклонения содержания и формы юридического документа от норм действующего законодательства, а также от объективного развития общественных отношений.

Данная тема актуальна, так как на сегодняшний день многие юридические документы содержат дефекты, препятствуя реализации прав граждан. Некоторые из дефектов на первый взгляд кажутся незначительными, однако при возникновении конкретных ситуаций могут существенно затруднить или сделать невозможной реализацию прав и свобод. Например, множество проблем может доставить

Соколова М. А. Качество юридических документов как условие их правовой состоятельности // Право и государство: теория и практика. 2013. № 2. С. 40-43. неверное написание фамилии гражданина, отсутствие того или иного реквизита документа.

Слово «дефект» происходит от латинского «defectus», что в переводе означает «недостаток» ${ }^{2}$. В русский язык данный термин пришел либо из голландского, либо из немецкого языка в начале XVIII века ${ }^{3}$. В «Толковом словаре русского языка» С.И. Ожегова дается следующее определение: «дефект - изъян, недостаток, недочет» ${ }^{4}$.

На сегодняшний день большинство объектов материального мира является продуктом человеческой деятельности. Многие из них содержат изъяны, обусловленные теми или иными нарушениями, допущенными в ходе осуществления деятельности по их созданию, изменению и переработке.

\footnotetext{
2 Латинский словарь онлайн $<$ http://www.latin.slovaronline.com/D/DE/2004DEFECTUS> (последнее посещение - 6 января 2014 г.).

3 Семенов А. В. Этимологический словарь русского языка. <http://evartist.narod.ru/text15/008.htm\#\%D0\%B7_13> (последнее посещение - 6 января 2014 г.).
}

4 Ожегов С.И. Толковый словарь русского языка. М., 1999. C. 163. 
Под дефектом человеческой деятельности следует понимать изъян, допущенный намеренно или без умысла в процессе осуществления данного вида человеческой деятельности, приведший к созданию некачественного результата (продукта) человеческой деятельности, а также изъян, возникший намеренно или без умысла в процессе последующего использования продукта человеческой деятельности. Таким образом, в зависимости от стадии осуществления деятельности можно выделить два вида дефектов:

- дефекты, заложенные изначально (в процессе создания результата человеческой деятельности);

- дефекты, возникшие в процессе использования продукта человеческой деятельности.

Юридические документы, в свою очередь, являются результатом одной из разновидностей человеческой деятельности. Примером дефекта, заложенного изначально, может служить часть 1 статьи 48 Конституции Российской Федерации ${ }^{5}$. Провозглашая право на квалифицированную юридическую помощь, ни данная норма, ни обеспечивающие ее нормы федерального законодательства не уточняют, какие именно субъекты вправе оказывать данную помощь. Это приводит к нарушению прав граждан: оказанию юридической помощи лицами, не имеющими высшего юридического образования, ограниченно дееспособными и т.п.

К дефектам, возникшим в процессе использования продукта человеческой деятельности, можно отнести необеспеченность правовой нормы экономическими, организационными и иными ресурсами. В данном случае текст самой нормы не содержит в себе каких-либо изъянов, но ее реализация затруднена либо невозможна. Примером может служить статья 8 Федерального закона «0 дополнительных гарантиях по социальной поддержке детей-сирот и детей, оставшихся без попечения родителей»: право на благоустроенное жилое помещение в законе закреплено ${ }^{6}$, но на практике существует много трудностей,

\footnotetext{
Конституция Российской Федерации (принята всенародным голосованием 12.12.1993) (с учетом поправок, внесенных законами РФ о поправках к Конституции РФ от 30.12.2008 № 6-ФКЗ, от 30.12.2008 № 7-ФКЗ от 05.02.2014 № 2-ФКЗ) // Российская газета. 25.12.1993. № 237; 21.01.2009. № 7; Собрание законодательства РФ. 03.03.2014. № 9. Ст. 851.

6 Федеральный закон от 21.12.1996 № 159-Ф3 «О дополнительных гарантиях по социальной поддержке детей-сирот и детей, оставшихся без попечения родителей» // Российская газета. 27.12.1996. № 248; 11.02 .1998 . № $26 ; 11.08 .2000$. № $155 ; 10.04 .2002$. № $64 ; 14.01 .2003$. № 4; 31.08.2004. № 188; 22.12.2009. № 246; 21.11.2011. № $261 ; 23.11 .2011$. № 263; 02.03.2012. № 46; 05.07.2013. № 145; 10.07.2013. № 148; 27.11.2013. № 267.
}

связанных с его реализацией, в первую очередь они обусловлены нехваткой жилого фонда.

Рассмотрев общее понятие дефекта, остановимся на правовой категории «дефект в праве». С.И. Цыбуляк рассматривает данное понятие в широком и узком значениях. В широком смысле под дефектом в праве автор понимает такое состояние правовых норм, при котором регулирование общественных отношений нарушает оптимальный баланс интересов личности, общества, государства. В узком смысле под правовым дефектом, по мнению С.И. Цыбуляка, следует понимать низкое качество правового регулирования, в силу которого затрудняется применение правовых норм, порождаются негативные политические и социально-экономические явления, ущемляются личные и общественные интересы ${ }^{7}$.

Мы считает, что оба определения не лишены недостатков. Первое - слишком абстрактно и субъективно: автор не конкретизирует, о каких именно интересах идет речь; понимание оптимального баланса интересов личности и государства также не единообразно и в первую очередь зависит от политического режима. Второе определение содержит в себе оценочную категорию - что понимать под «низким качеством»? И можно ли говорить о качестве вообще при наличии тех или иных дефектов?

Суслова Н.В., изучая сущность дефектов в праве, отмечает, что дефект права прежде всего есть следствие дефектов мышления, так как текст любого источника права есть внешняя форма воплощения юридического мышления его создателя ${ }^{8}$. С этим безусловно следует согласиться.

Вопрос о причинах возникновения дефектов в праве получил свое развитие в работах Г.Р. Сибгатуллиной. В статье «Дефекты права: причины и механизмы их устранения» она отмечает несколько важных положений. Во-первых, автор отграничивает понятие «дефект в праве» от понятия «юридическая ошибка», считая юридическую ошибку разновидностью дефекта, так как дефекты могут быть допущены не только по неосторожности (ввиду невнимательности, низкой квалификации законодателя), но и умышленно9.

Цыбуляк С. И. Дефекты конституционно-правового регулирования избирательных отношений в Российской Федерации: Автореф. дисс. ... канд. юрид. наук. Тюмень, 2010. С. 7-8.

Суслова Н. В. Дефекты права. Причины образования // Проблемы права. 2013. № 1. С. 126-131.

9 Сибгатуллина Г. Р. Дефекты права: причины и механизмы их устранения // URL: http://old.tisbi.org/science/ vestnik/2010/issue3/Low/Sibgatullina.html (Дата обращения: 01.02.2014). 
Мы считаем, что данное разграничение целесообразно, особенно применительно к вопросу о способах предупреждения и устранения дефектов, так как методы противодействия какому-либо явлению тесно связаны с причинами его возникновения. Под юридической ошибкой следует понимать изъяны, допущенные в ходе осуществления правовой деятельности, а также в продукте правовой деятельности ввиду добросовестного заблуждения субъекта, ее осуществляющего. Во-вторых, анализирует причины возникновения дефектов в праве.

Муругина В.В. изучала проблему дефектности юридических фактов. В своей работе автор формулирует определение понятия «дефектный юридический факт», понимая под ним особый вид юридических фактов, имеющий в своем юридическом составе дефект и (или) несоответствие реальному отражаемому действию (событию) и, как следствие, вызывающий правовые последствия в виде недействительности и восстановления нарушенного права ${ }^{10}$.

Мы считаем, что данное определение нуждается в некоторой корректировке. Во-первых, в нем отсутствует указание на единое основание классификации юридических фактов. Во-вторых, предпринимается попытка определения понятия через определяемое слово, значение которого также не расшифровывается. Что понимать под дефектом в данном контексте? В-третьих, несоответствие факта реальному отражаемому действию представляет собой одну из разновидностей дефекта, следовательно, должно включаться в содержание данного понятия.

Власенко Н.А. предлагает определение дефектов системы права: дефект системы права - это нарушение, деформация логикоструктурного построения и развития системы права и её элементов, в том числе нормативных актов ${ }^{11}$.

Многие ученые рассматривали дефекты конкретных правовых актов. Для нас данные работы представляют интерес с точки зрения выявления существенных признаков более крупной (с точки зрения логического объема) правовой категории - дефект юридического документа.

Зуев О.М. формулирует определение категории «юридически дефектный нормативный правовой акт», понимая под ним «...письменный официальный документ, принятый субъ-

10 Муругина В. В. Дефектность юридических фактов как негативная черта правовой системы: Автореф. дисс. ... канд. юрид. наук. Саратов, 2010.

11 Власенко Н. А. Логико-структурные дефекты системы советского права // Правоведение. 1991. № 3. C. 21-26. ектом правотворчества в нарушение его компетенции либо с нарушением содержательных и (или) процедурно-процессуальных требований, и (или) несоответствующий закону или нормативному правовому акту более высокой юридической силы» ${ }^{12}$. На наш взгляд, данное определение является достаточно полным, так как отражает основные признаки определяемого понятия. Единственно, возникает сомнение насчет необходимости выделения в отдельный признак несоответствия принимаемого нормативно-правового акта закону или иному нормативному правовому акту. По нашему мнению, представляется наиболее целесообразным включить данный вид дефектов в дефекты содержания.

Кисличенко Е.И. рассматривает понятие «дефект законодательства». В теории права термин «законодательство» имеет два значения. Такие ученые, как Р.З. Лившиц ${ }^{13}$, Ю.А. Тихомиров $^{14}$, считают, что под законодательством следует понимать только совокупность законов. С.В. Поленина ${ }^{15}$, О.А. Красавчиков ${ }^{16}$, С.С. Алексеев ${ }^{17}$ включают в понятие законодательства не только законы, но и иные нормативные правовые акты. Отсюда вытекает, что и дефекты законодательства могут пониматься в широком и узком значениях.

В широком смысле под дефектом законодательства Е.И. Кисличенко понимает «такое состояние законов, а, как следствие, и других нормативных правовых актов, при котором правовое регулирование общественных отношений нарушает оптимальный баланс интересов человека, общества и государства, порождаются негативные политические и социально-экономические явления, необоснованно ущемляются личные и общественные интересы». На наш взгляд, данное определение не совершенно. Что понимать под балансом интересов? Как уже отмечалось, данная формулировка весьма неоднозначна. Из логического анализа определения вытекает, что обоснованное ущемление интересов допустимо. Возникает вопрос: какие обстоятельства могут повлечь обоснованное ущемле-

12 Зуев О. М. Юридически дефектные нормативноправовые акты в системе источников права: дисс. ... канд. юрид. наук. Москва, 2011. С. 17-18.

13 Лившиц Р. 3. Теория права. М., 1994. С. 111.

14 Тихомиров Ю. А. Юридическая коллизия. М., 1994. C. 33 .

15 Поленина С. В. Российское законодательство: проблемы и перспективы. М., 1995. С. 4-5.

16 Красавчиков О. А. Система права и система законодательства (гражданско-правовой аспект) // Правоведение. 1975. № 2. С. 68.

Алексеев С. С. Право: азбука, теория, философия: опыт комплексного исследования. М., 1999. С. 83. 
ние? В определении они не упомянуты. В узком смысле дефект законодательства - это «низкое качество закона, в силу которого затрудняется формирование системы правового регулирования, возникают проблемы реализации соответствующих правовых норм» ${ }^{18}$.

Многие авторы формулировали определение дефекта права применительно к конкретным отраслям. В частности, С.А. Авакьян занимался выявлением сущности дефектов конституционного права. Анализируя конституционные нормы, автор пришел к выводу, что все дефекты права есть не что иное, как результат изъянов идей, в последующем нашедших свое закрепление в законодательстве, в том числе конституционном ${ }^{19}$. Мы разделяем позицию автора: законодательство создается людьми, изъяны мышления проецируются в юридические тексты.

Жильцов М.А. фундаментально исследовал дефекты трудового права, понимая под ними «недостатки, противоречия, несовершенство трудовых правовых норм и конструкций, которые приводят к проблемам правоприменения, нарушению трудовых прав и законных интересов субъектов трудовых и иных непосредственно связанных с ними отношений» ${ }^{20}$.

Андреев Д.С. формулирует определение дефектного административно-правового акта. По его мнению, дефектный административно-правовой акт - это акт, соответствующий признакам административно-правовых актов, но не соответствующий предъявляемым к ним требованиям законности ${ }^{21}$. На наш взгляд, данное определение алогично: определяемое понятие шире предлагаемого определения. Под требованиями законности понимаются императивные предписания закона, направленные на практическую реализацию принципов права. Безусловно, административно-правовой акт, противоречащий закону, будет считаться дефектным, однако, дефектность административно-правовых актов не исчерпывается нарушением требований законности, включая логические, лингвистические, организационные и иные изъяны.

\footnotetext{
18 Кисличенко Е. И. Дефекты законодательства субъектов Российской Федерации в сфере местного самоуправления: на примере республики Марий-Эл: автореферат дисс. ... канд. юрид. наук Казань, 2012.

19 Авакьян С. А. Пробелы и дефекты в конституционном праве и пути их устранения // Конституционное и муниципальное право. 2007. № 8. С. 3-12.

20 Жильцов М. А. Дефекты трудового права и способы их преодоления: автореферат дисс. ... канд. юрид. наук. Екатеринбург, 2011.

21 Андреев Д. С. Дефектные административно-правовые акты: автореф. дисс. ... канд. юрид. наук. М., 2011.
}

Помимо дефектов актов правотворчества в научной литературе также рассматривались дефекты правоприменительных актов. В частности, О.В. Хусаинова анализирует причины и условия возникновения дефектов в правоприменительных актах. Она отмечает, что дефектные акты правоприменения возникает не только вследствие нарушений правил юридической техники, но и ввиду выбора ненадлежащих средств достижения поставленной цели, несоблюдения принципов права, отсутствия критериев качества правоприменительной деятельности как таковой ${ }^{22}$. На проблему взаимосвязи качества законодательной техники и правоприменения обратил внимание Н.Н. Ковтун ${ }^{23}$. На примере анализа уголовно-процессуальных норм (выявления многочисленных коллизий и неоднозначности формулировок) он показывает: как данные дефекты закона препятствуют принятию качественных правоприменительных документов, а также затрудняют реализацию уже принятых.

На наш взгляд, под дефектом акта правоприменения следует понимать изъян в содержании и (или) форме правоприменительного документа, возникший ввиду умышленной или ошибочной деятельности правоприменителя, а также ввиду наличия изъяна в нормах нормативного правового акта, на основании которого создан правоприменительный документ.

Каргин К.В. предлагает определение дефекта в юридическом документе. Он пишет: «Дефект в юридическом документе - это изъян, недостаток, допущенный участником правовых отношений, непосредственно разрабатывающим данный юридический документ или имеющим возможность воздействовать на его разработку, который влечет или может повлечь за собой нежелательные правовые или иные последствия» ${ }^{24}$.

Проанализировав различные определения понятия «дефект», рассмотрим основные признаки дефекта юридического документа.

Во-первых, дефект юридического документа - это изъян. Наряду с понятием «изъян» в литературе часто используются такие синонимы, как недостаток, погрешность, недо-

22 Хусаинова О. В. Правоприменительная деятельность органов государственной власти: оценка эффективности, основные направления совершенствования (теоретико-правовой аспект): автореф. дисс. ... канд. юрид. наук. Казань, 2009.

23 Ковтун Н. Н. Дефекты законодательной техники вызывают трудности в правоприменении // Российская юстиция. 2001. № 8. С. 39-40.

24 Каргин К. В. Юридические документы. Монография. М.: Юрист, 2007. С. 160. 
чет $^{25}$. Однако, на наш взгляд, понятие «изъян» является наиболее точным. Одним из однокоренных слов понятия «недостаток» является глагол «недостает» (в значении «не хватает»), следовательно, под недостатком (в одном из значений данного слова) понимается отсутствие чего-либо нужного. Но дефект юридического документа может быть обусловлен не только отсутствием чего-либо, например необходимых реквизитов, но и излишеством, например, дублированием правовых положений, наличием лишних реквизитов. Понятие «погрешность» также является более узким по значению, чем понятие «изъян» (с точки зрения формальной логики, они находятся в отношении подчинения). В словаре С. Ожегова погрешность определяется как «ошибка, промах» ${ }^{26}$. Иначе говоря, погрешность, в том числе в юридическом документе, продукт неумышленной деятельности лица, в то время как дефект юридического документа может быть допущен и умышленно, например, с целью незаконного получения прав, освобождения от возложенных на лицо обязанностей. Наконец понятие недочет также не отражает полноты содержания понятия «дефект», так как касается только несущественных дефектов, допущенных неумышленно.

Во-вторых, данный изъян состоит в несоответствии оформления, содержания, структуры юридического документа нормам законодательства, а также потребностям правового регулирования общественных отношений. Прежде всего необходимо отметить, что несоответствие может касаться как одного элемента, так и нескольких из них или всех. Что касается оснований несоответствия, то таковыми могут быть как нормы законодательства, так как они являются основой всей правовой материи и задают определенные стандарты как для нижестоящих нормативных актов, так и для актов применения, иных актов, так и объективные потребности общества и государства, обусловленные развитием экономических, политических, социальных, культурных и иных общественных отношений. Теоретически объективные потребности в правовом регулировании должны находить свое отражение в принципах права, однако на практике данная модель является идеалистической и не соответствует реальности. Закре-

25 Например, см.: Сибгатуллина Г. Р. Дефекты права: причины и механизм устранения //URL: http:/old.tisbi. org/science/vestnik/2010/issue3/Low/Sibgatullina.html (Дата обращения: 01.02.2014).

26 СловарьОжегова.Толковыйсловарьрусскогоязыка// < http://www.ozhegov.org/words/23973.shtml> (последнее посещение - 10 февраля 2014 г.). пленные принципы права также продукт деятельности законодателя, следовательно, они могут быть навязаны обществу и проводить в жизнь интересы отдельных групп либо просто декларироваться с целью внешнего соответствия права международным стандартам. Таким образом, потребности общества и принципы права могут не совпадать между собой. В выделяемом нами признаке понятия «дефект юридического документа» речь идет именно о потребностях общества, так как только в этом случае мы сможем обеспечить эффективность принимаемых актов.

В-третьих, дефект юридического документа возникает в результате деятельности лиц, создающих, принимающих, изменяющих юридические документы ${ }^{27}$. Иными словами, между деятельностью лиц, создающих, принимающих, изменяющих юридические документы, и качеством последних существует тесная детерминистическая (причинно-следственная) связь. Дефект юридического документа результат умышленных или ошибочных (непреднамеренных) действий создателей (в широком смысле этого слова), а также иных лиц, изменяющих, дополняющих, применяющих юридический документ.

В-четвертых, дефект юридического документа влечет за собой ухудшение качества юридического документа, так как юридический документ, как уже отмечалось, перестает соответствовать требованиям законодательства, а также потребностям общества и государства в соответствующем регулировании общественных отношений. Стоит отметить, что дефект влечет именно ухудшение качества, а не его снижение. Понятие «низкое качество» является оценочным. Следовательно, по мнению одного лица, документ может быть низкого качества, по мнению другого - среднего и т.д. Понятие «ухудшение» не несет в себе оценочной окраски. Под ухудшением в данном контексте понимается такое изменение качества, которое ведет к частичному или полному несоблюдению требований, предъявляемых к юридическому документу законодательством, а также частичному или полному несоответствию юридического документа потребностям человека, общества и государства.

Таким образом, мы можем сформулировать следующее определение дефекта юридического документа: дефект юридического документа - это изъян, состоящий в несоответствии формы, содержания, структу-

\footnotetext{
27 Каргин К. В. Юридические документы. Монография. М.: Юрист, 2007. С. 161.
} 
ры юридического документа нормам законодательства, а также потребностям правового регулирования общественных отношений, возникающий в результате умышленной или ошибочной деятельности лиц, создающих, принимающих, перерабатывающих юридические документы, и влекущий за собой ухудшение качества юридического документа.

\section{Библиография:}

1. Авакьян С. А. Пробелы и дефекты в конституционном праве и пути их устранения // Конституционное и муниципальное право. - 2007. - № 8. - С. 3-12.

2. Алексеев С. С. Право: азбука, теория, философия: опыт комплексного исследования. М., 1999.$169 \mathrm{c.}$

3. Андреев Д. С. Дефектные административно-правовые акты: автореф. дисс. ... канд. юрид. наук. М., 2011.

4. Власенко Н. А. Логико-структурные дефекты системы советского права // Правоведение. 1991. - № 3. - С. 21-26.

5. Жильцов М. А. Дефекты трудового права и способы их преодоления: автореф. дисс. ... канд. юрид. наук. Екатеринбург, 2011.

6. Зуев О. М. Юридически дефектные нормативно-правовые акты в системе источников права: дисс. ... канд. юрид. наук. Москва, 2011. - 193 с.

7. Каргин К. В. Юридические документы. Монография. М.: Юрист, 2008. - 191 с.

8. Кисличенко Е. И. Дефекты законодательства субъектов Российской Федерации в сфере местного самоуправления: на примере республики Марий-Эл: Автореф. дисс. ... канд. юрид. наук. Казань, 2012.

9. Ковтун Н. Н. Дефекты законодательной техники вызывают трудности в правоприменении // Российская юстиция. - 2001. - № 8. - С. 39-40.

10. Красавчиков О.А. Система права и система законодательства (гражданско-правовой аспект) // Правоведение. - 1975. - № 2. - С. 62-71.

11. Лившиц Р. 3. Теория права. М., 1994. - 224 с.

12. Муругина В. В. Дефектность юридических фактов как негативная черта правовой системы: Автореф. дисс. ...канд. юрид. наук. Саратов, 2010.

13. Поленина С. В. Российское законодательство: проблемы и перспективы. М., 1995. - 478 с.

14. Сибгатуллина Г. Р. Дефекты права: причины и механизмы их устранения // URL: http://old. tisbi.org/science/vestnik/2010/issue3/Low/Sibgatullina.html (Дата обращения: 01.02.2014).

15. Соколова М. А. Качество юридических документов как условие их правовой состоятельности // Право и государство: теория и практика. - 2013. - № 2. - С. 40-43.

16. Суслова Н. В. Дефекты права. Причины образования // Проблемы права. - 2013. - № 1. C. $126-131$.

17. Тихомиров Ю. А. Юридическая коллизия. М., 1994. - 230 с.

18. Хусаинова О. В. Правоприменительная деятельность органов государственной власти: оценка эффективности, основные направления совершенствования (теоретико-правовой аспект): автореф. дисс. ... канд. юрид. наук. Казань, 2009.

19. Цыбуляк С. И. Дефекты конституционно-правового регулирования избирательных отношений в Российской Федерации: автореф. дисс. ... канд. юрид. наук. Тюмень, 2010. - 22 с.

\section{References:}

1. Avak'yan S. A. Probely i defekty v konstitutsionnom prave i puti ikh ustraneniya // Konstitutsionnoe i munitsipal'noe pravo. - 2007. - № 8. - S. 3-12.

2. Alekseev S. S. Pravo: azbuka, teoriya, filosofiya: opyt kompleksnogo issledovaniya. M., 1999. - 169 s.

3. Andreev D. S. Defektnye administrativno-pravovye akty: avtoref. diss. ... kand. yurid. nauk. M., 2011.

4. Vlasenko N. A. Logiko-strukturnye defekty sistemy sovetskogo prava // Pravovedenie. -1991. № 3. - S. 21-26.

5. Zhil'tsov M. A. Defekty trudovogo prava i sposoby ikh preodoleniya: Avtoref. diss. ... kand. yurid. nauk. Ekaterinburg, 2011.

6. Zuev O. M. Yuridicheski defektnye normativno-pravovye akty v sisteme istochnikov prava: diss. ... kand. yurid. nauk. - Moskva, 2011. - 193 s.

7. Kargin K. V. Yuridicheskie dokumenty. Monografiya. M.: Yurist, 2008. - 191 s.

8. Kislichenko E. I. Defekty zakonodatel'stva sub"ektov Rossiiskoi Federatsii v sfere mestnogo samoupravleniya: na primere respubliki Marii-El: avtoref. diss. ... kand. yurid. nauk. Kazan', 2012. 
9. Kovtun N. N. Defekty zakonodatel'noi tekhniki vyzyvayut trudnosti v pravoprimenenii // Rossiiskaya yustitsiya. - 2001. - № 8. - S. 39-40.

10. Krasavchikov 0. A. Sistema prava i sistema zakonodatel'stva (grazhdansko-pravovoi aspekt) // Pravovedenie. - 1975. - № 2. - S. 62-71.

11. Livshits R. Z. Teoriya prava. - M., 1994. - 224 s.

12. Murugina V. V. Defektnost' yuridicheskikh faktov kak negativnaya cherta pravovoi sistemy: Avtoref. diss. ...kand. yurid. nauk. Saratov, 2010.

13. Polenina S. V. Rossiiskoe zakonodatel'stvo: problemy i perspektivy. M., 1995. - 478 s.

14. Sibgatullina G. R. Defekty prava: prichiny i mekhanizmy ikh ustraneniya. //URL: http://old.tisbi. org/science/vestnik/2010/issue3/Low/Sibgatullina.html (Data obrashcheniya: 01.02.2014).

15. Sokolova M. A. Kachestvo yuridicheskikh dokumentov kak uslovie ikh pravovoi sostoyatel'nosti // Pravo i gosudarstvo: teoriya i praktika. - 2013. - № 2. - S. 40-43.

16. Suslova N. V. Defekty prava. Prichiny obrazovaniya // Problemy prava. - 2013. - № 1. - S. 126-131.

17. Tikhomirov Yu. A. Yuridicheskaya kolliziya. M., 1994. - $230 \mathrm{~s}$.

18. Khusainova 0. V. Pravoprimenitel'naya deyatel'nost' organov gosudarstvennoi vlasti: otsenka effektivnosti, osnovnye napravleniya sovershenstvovaniya (teoretiko-pravovoi aspekt): Avtoref. diss. ... kand. yurid. nauk. Kazan', 2009.

19. Tsybulyak S. I. Defekty konstitutsionno-pravovogo regulirovaniya izbiratel'nykh otnoshenii v Rossiiskoi Federatsii: avtoref. diss. ... kand. yurid. nauk. Tyumen', 2010. - 22 s.

Материал поступил в редакцию 20 марта 2014 г. 